\title{
Voltage Stability Assessment using GVSM and Preventive Control using SVC
}

\author{
Ankit Kumar Sharma \\ Research Scholar \\ Department of Electrical \\ Engineering, SKIT, Jaipur, \\ India
}

\author{
Akash Saxena \\ Reader \\ Department of Electrical \\ Engineering, SKIT, Jaipur, \\ India
}

\author{
Rajive Tiwari \\ Associate Professor \\ Malaviya National Institute of \\ Technology, Jaipur, \\ India
}

\begin{abstract}
Voltage stability is a major concern while designing a foolproof power network. In recent years deregulated environment put an additional pressure on transmission and distribution utilities. With this fact assessment of voltage stability along with the preventive control actions are major area of research. With this motivation, this paper presents assessment of voltage stability through Global Voltage Stability Margin (GVSM). GVSM is an indicator of the system's health from a voltage stability perspective. Three standard IEEE bus systems are simulated with different loading scenarios. Static Var Compensator (SVC) has employed for preventive control in collapse condition. The location of SVC is finalised through weak bus identification methods. Voltage stability indices namely Fast Voltage Stability Indice (FVSI) and $\mathrm{L}_{\mathrm{mn}}$ are utilized to identify weak buses in the systems. For calculation of the Size of SVC, an optimization routine is established. This routine has an aim to maximize the GVSM. Gravitational Search Algorithm (GSA) is used for the optimization. The results obtained from proposed method are promising.
\end{abstract}

\section{General Terms}

Flexible AC Transmission System (FACTS), Voltage Stability Assessment, Static VAR Compensators.

\section{Keywords}

Global Voltage Stability Margin (GVSM), Fast Voltage Stabilty Index (FVSI), Gravitational Search Algorithm (GSA) and IEEE test bus systems

\section{INTRODUCTION}

Modern power system has emerged as a complex network due to exponential increase in demand and competitive business environment. Escalating demands put a stress on the existing network. Transmission network expansion can be a solution for this but it requires time to expand this utility. Complexity of the power networks becomes manifold in deregulation environment. There is acute need of the technique for assessment the critical point of the voltage stability. Stressed transmission network is prone to voltage collapse. Therefore, voltage stability analysis is necessary to identify the critical buses in a power system i.e., buses which are closed to their voltage instability and to help the planning engineers and operators to take appropriate actions to avoid and overcome the problem of voltage collapse $[1,3]$. The common techniques available for the assessment of voltage stability of any power system as well as for identifying the point of critical voltage stability are based on the load flow solution feasibility [3], bifurcation technique[3], singularity of Jacobian [1,3] and optimal power flow [1]. Mostly used techniques are, the conventional $\mathrm{Q}-\mathrm{V}, \mathrm{P}-\mathrm{V}$ curves and $\mathrm{P}-\mathrm{Q}$ plane $[2,3]$ for assessing the voltage stability of critical bus in a power system. The Weak area of the Practical system and the Ranking with overloading are examined by using FVSI and Lmn [1]. P.Nagendra et. al. [1] discussed about the development of equivalent pi-network using series and shunt parts of the line. Power losses were separately obtained from the operational parameters of OPF solution of the original multi bus power network. The voltage stability status was assessed by GVSM. M.H.Haque et. al. [2] used V-I characteristics to assessed the voltage stability limit. Bus voltage and current data of present $\&$ immediate past at operating points were employed in this approach. These data processed through the least square method to develop the V-I characteristics [2]. F.Gubina et. al. [4, 5] represented the phasor concept for determination of VCPI. K.R.Vadivelu et al. [6] discussed voltage stability analysis using line stability index. C M Arora et. al. [7] discussed the repeated power flow technique to the study the consequences of loadability on voltage stability. Claudia Reis et. al. [8] presented a comparative analysis of the performance of static voltage collapse indices. The voltage stability margin analyzed by using P-V and Q-V curves and L-index by Kessel et. al. [9], V/Vo index, was proposed by N. D. Hatziargyriou [10], Line stability index Lmn and VCPI was proposed by M.Moghavemmi et al [11], Line stability index FVSI was proposed by I. Musirin et. al. [12, 13], Line stability index LQP was proposed by A. Mohamed et. al. [14], Krishna Nandlal et. al. [15] developed a voltage stability assessment MATLAB toolbox for marginal and analytical assessment of voltage stability. Z.J.Lim et. al. [16] and M.V.Suganyadevi et. al. [17] discussed various voltage stability indices namely Lnm, FVSI, LQP, LP and NLSI. The values of FVSI indicated the voltage stability condition in the power system and it used to rank the line contingency [13]. Ismail Musirin et. al. [13] discussed simplified from of FVSI. A pre-developed VSI referred to a line initiated from the voltage quadratic equation at sending end of 2-bus system and results of proposed index are verified by using line index Lmn and LQP [13]. Rajive Tiwari et. al. [18] discussed about a new index named Line collapse proximity index (LCPI) for assessment of voltage stability. This index based on exact model of transmission system. This index was compared with FVSI, Lmn and LQP indices at different loading conditions. O. P. Rahi et. al. [19] developed a new technique for determine the static voltage stability of load buses in a power system for different operating conditions and identifies the load buses which are near to voltage collapse. L.D.Arya et. al. [20] described an algorithm for the rescheduling of reactive power control variables so as to have an adequate loadability margin for current operating point. Co-ordinated aggregation based PSO (CAPSO) has been used as an optimization technique. 
Different methods for determining the locations of shunt SVCs for voltage stability enhancement were presented in [21]. Recent years application of metaheuristic techniques is increased in real problems. E Rashedi et. al. [22] developed Gravitational Search Algorithm which was based on the gravitational law. Saxena Akash et. al. [23] gave chronological review and comparison of four Evolutionary based algorithms, named Genetic Algorithm (GA), Gravitational Search Algorithm (GSA), Cuckoo Search Algorithm (CSA) and PSO.

In the view of literature survey, following research objectives are formed for this paper.

a. To present the mathematical frame work of GVSM, calculate the same for three standard IEEE networks (14, 30 and 118 bus).

b. To identify the weak buses in networks by the application of line voltage stability indices.

c. To formulate an optimization routine with the aim of maximization of GVSM. To solve this routine by GSA. Further, the routine will suggest the size of SVC on identified weak buses.

d. To present the comparison of the system GVSM with and without SVC.

Rest part of the paper is organised as follows in section 2 and 3 mathematical frame work of GVSM, FVSI and Lmn are presented. In section 4, brief details of GSA are incorporated. In section 5 simulation results are presented last but not the least in section 6 conclusion and future scope of the work is presented.

\section{GLOBAL VOLTAGE STABILITY MARGIN (GVSM)}

When the two-bus network equivalent of a multi bus power system is obtained, the global voltage stability indices can be formulated from the parameters of the global network. Here the voltage-current relation in the form of $\mathrm{ABCD}$ parameters for pi-equivalent two-bus circuit of the transmission line, is given by Eq. (1).

$\left[\begin{array}{c}V_{s} \\ I_{s}\end{array}\right]=\left[\begin{array}{ll}A & B \\ C & D\end{array}\right]\left[\begin{array}{c}V_{r} \\ I_{r}\end{array}\right]$

Where

$A=D=1+\frac{Y Z}{2} ; B=Z ; C=Y\left(1+\frac{Y Z}{4}\right)$

Assuming

$$
\left[Z=Z_{s e_{-} e q} \text { and } \frac{Y}{2}=Y_{s h_{-} e q}\right]
$$

Let as assume

$$
A=|A| \angle \alpha ; B=|B| \angle \beta ; \vec{V}_{s}=\left|\vec{V}_{s}\right| \angle \theta ; \vec{V}_{r}=\left|\vec{V}_{r}\right| \angle \delta ; \delta<\theta
$$

Solving for the receiving end current:

$$
I_{r}=\frac{\left|\vec{V}_{s}\right|}{|B|} \angle \theta-\beta-\frac{|A|\left|\vec{V}_{r}\right|}{|B|} \angle \alpha-\beta+\delta
$$

Complex power of receiving end is given by Eq. (3),

$$
S_{r}=\vec{V}_{r} \vec{I}_{r}^{*}=\left|\vec{V}_{r}\right| \angle \delta\left[\frac{\left|\vec{V}_{s}\right|}{|B|} \angle-\theta+\beta-\frac{|A| \vec{V}_{r} \mid}{|B|} \angle-\alpha+\beta-\delta\right]
$$

The active and reactive powers at the receiving end are given by:

$$
\begin{aligned}
& P_{r}=\frac{\left|\vec{V}_{r}\right|}{|B|} \cos (\beta+\delta)-\frac{|A|\left|\vec{V}_{r}\right|^{2}}{|B|} \cos (\beta-\alpha) \\
& Q_{r}=\frac{\left|\vec{V}_{r}\right|}{|B|} \sin (\beta+\delta)-\frac{|A|\left|\vec{V}_{r}\right|^{2}}{|B|} \sin (\beta-\alpha)
\end{aligned}
$$

The Jacobian matrix is given by:

$$
\begin{aligned}
J & =\left[\begin{array}{ll}
\frac{\partial P_{r}}{\partial \delta} & \frac{\partial P_{r}}{\partial V_{r}} \\
\frac{\partial Q_{r}}{\partial \delta} & \frac{\partial Q_{r}}{\partial V_{r}}
\end{array}\right] \\
& =\frac{1}{|B|}\left[\begin{array}{c}
-\left|\vec{V}_{r}\right| \sin (\beta+\delta) \cos (\beta+\delta)-2|A|\left|\vec{V}_{r}\right| \cos (\beta-\alpha) \\
\left|\vec{V}_{r}\right| \cos (\beta+\delta) \sin (\beta+\delta)-2|A|\left|\vec{V}_{r}\right| \sin (\beta-\alpha)
\end{array}\right]
\end{aligned}
$$

The determinant of Jacobian matrix is given in Eq. (5):

$$
\Delta[J]=\frac{1}{|B|^{2}}\left[2|A|\left|\vec{V}_{r}\right|^{2} \cos (\delta+\alpha)-\left|\vec{V}_{r}\right|\right]
$$

At the critical point of voltage stability, $\Delta[J]=0$ is given in Eq. (6).

$$
\left|\vec{V}_{r}\right|=V_{c r}=\frac{1}{2|A| \cos (\delta+\alpha)}
$$

Here $\mathrm{Vcr}$ is the critical value of the receiving-end voltage at voltage stability limit. Low value of Vcr indicates the system will have better voltage profile along with higher load catering capability. To maintain global voltage stability, $\Delta[J]=0$. Therefore to secure global voltage stability, the global voltage stability margin can be defined as GVSM= $\Delta[J]$, given in Eq. (5). The value of GVSM indicates the margin between present operating condition and the point of voltage collapse [1].Figure 1 shows the flow of algorithm to compute GVSM, Critical Voltage, Global Receiving end Voltage. 


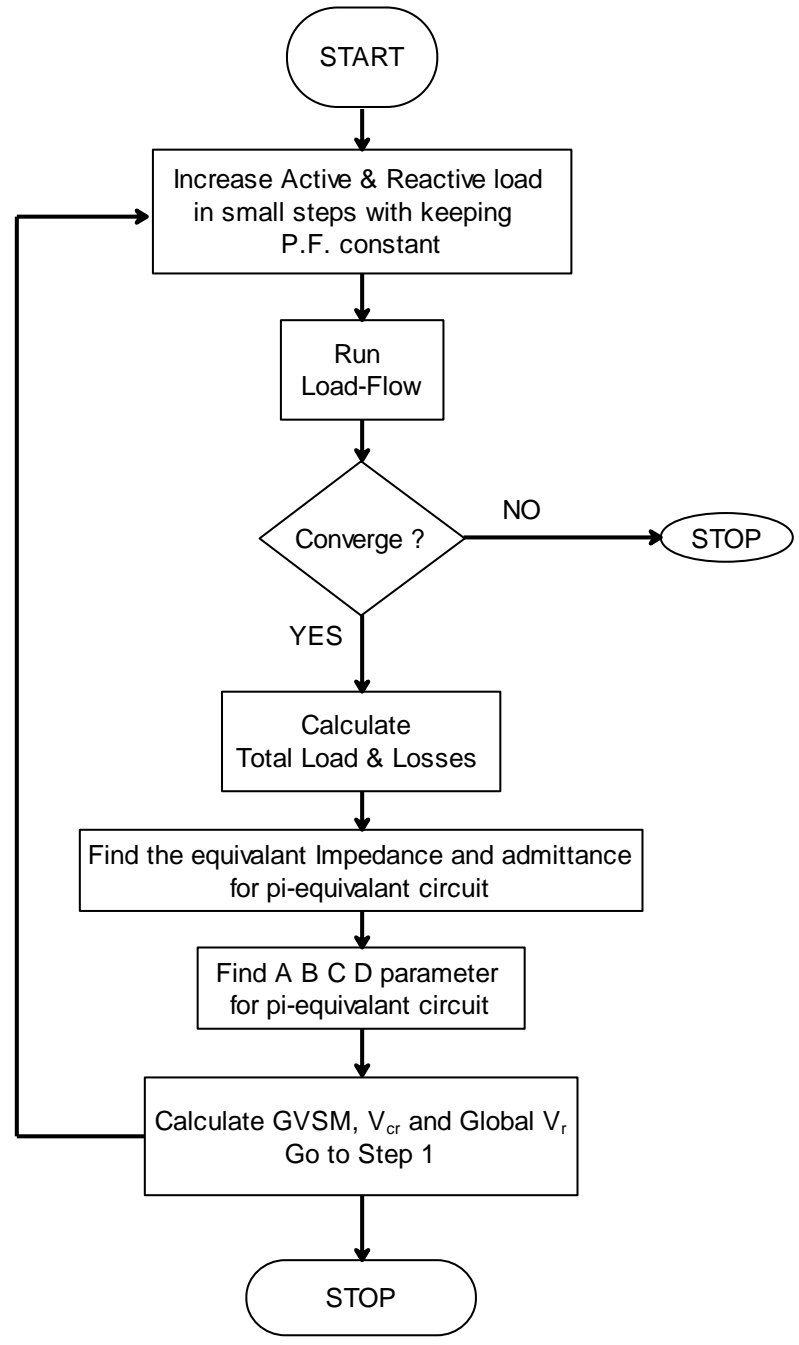

Fig 1: Algorithm to compute GVSM, Ver and Global Vr

\section{INDEX FORMULATION}

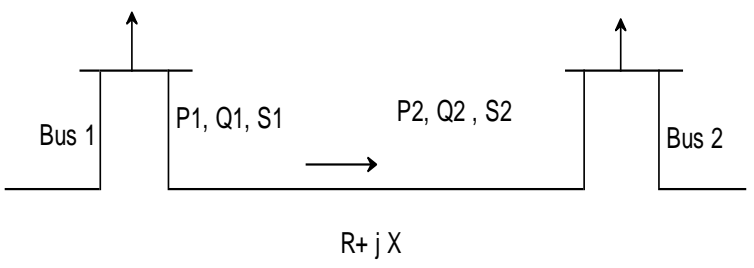

Fig 2: Two bus equivalent system

The FVSI is derived from the voltage quadratic equation at the receiving bus on a two-bus system. Figure 2 shows the two-bus system. Since "s" as the sending bus and "r" as the receiving end bus, since $\delta$ is normally very small $\&$ negligible, then, $\delta \approx 0, R \sin \delta \approx 0$ and $X \cos \delta \approx X$. Taking the symbols " $s$ " as the sending bus and " $r$ " as the receiving bus, FVSI can be calculated [8].

$$
F V S I_{s r}=\frac{4 Z^{2} Q_{r}}{V_{s}^{2} X}
$$

And

The Line Stability Index proposed by Mohavani and Omar (1998). It is symbolized by $\mathrm{L}_{\mathrm{mn}}$. The Line Stability Index is given by

$$
L_{m n}=\frac{4 Q_{r} X}{\left[\left|V_{s}\right| \sin (\theta-\delta)\right]^{2}}
$$

The result for bus ranking is based on maximum loadability using FVSI and Lmn. The bus ranking can be performed by sorting the maximum loadability in ascending order. The smallest maximum loadability will be ranked the highest implying the weakest bus in the system. Calculation of these indices can be carried out by adopting a procedure mentioned in Figure 3.

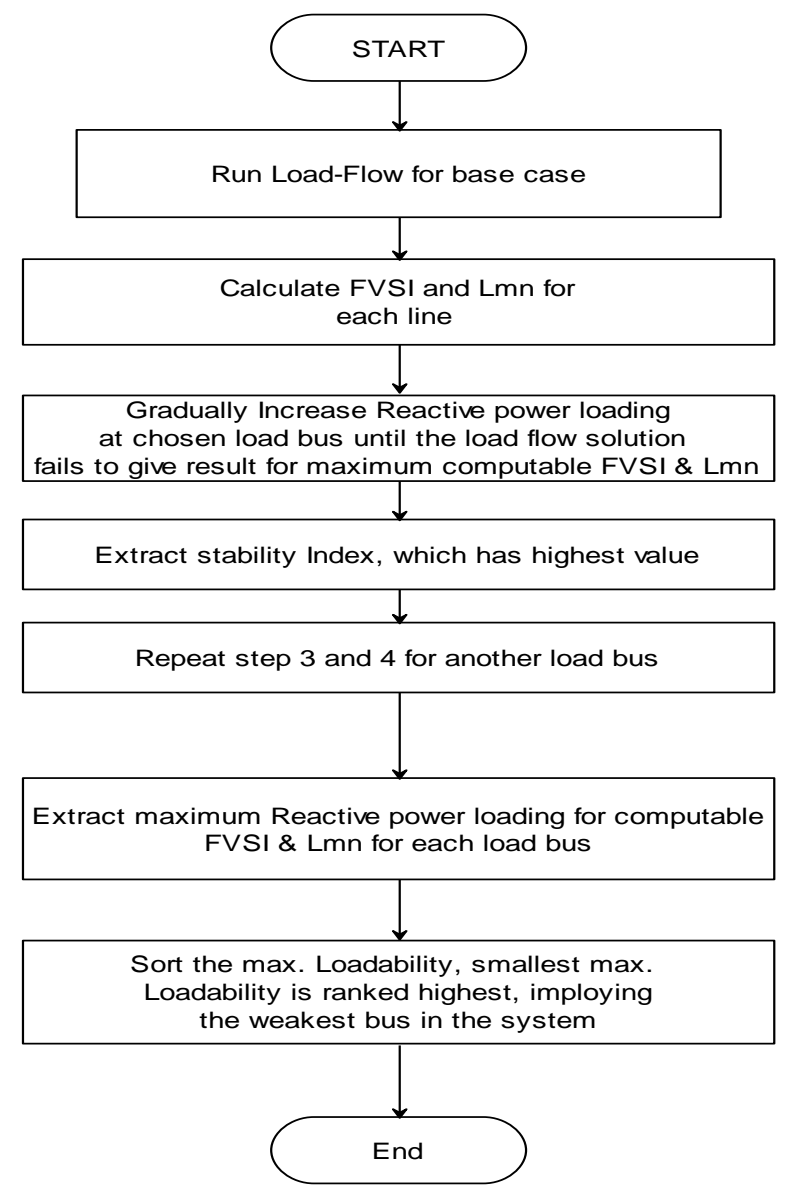

Fig 3: Proposed algorithm for determining the maximum loadability for weak bus identification

\section{OPTIMIZATION PROBLEM}

In this paper, two indices namely FVSI and Lmn are employed for weak bus identification. At high reactive loading the value of GVSM becomes low. The system is on the verge of collapse. The application of SVCs on weak buses is a corrective action in this condition. The choice of size of SVC is calculated by GSA for IEEE 14, 30, and 118 bus systems.

Maximization of GVSM:

$J=\max \left[\Delta\left[J \rrbracket=\max \left[\frac{1}{|B|^{2}}\left[\left.2|A| \vec{V}_{r}\right|^{2} \cos (\delta+\alpha)-\left|\vec{V}_{r}\right|\right]\right]\right.\right.$ (9)

Equality Constraints:

$P_{g i}-P_{d i}=V_{i} \sum_{j \in N_{i}} V_{j}\left(G_{i j} \cos \theta_{i j}+B_{i j} \sin \theta_{i j}\right) i \in N_{0}$ 
$Q_{g i}-Q_{d i}=V_{i} \sum_{j \in N_{i}} V_{j}\left(G_{i j} \sin \theta_{i j}-B_{i j} \cos \theta_{i j}\right) i \in N_{P Q}$

\section{Inequality Constraints:}

Generator Constraints:

$V_{i}^{\min } \leq V_{i} \leq V_{i}^{\max } \quad i \in N_{B}$

$Q_{G i}^{\min } \leq Q_{G i} \leq Q_{G i}^{\max } \quad i \in N_{G}$

Transformer Constraints:

$T_{k}^{\min } \leq T_{k} \leq T_{k}^{\max } \quad k \in N_{T}$

Shunt VAR Compensator Constraints:

$Q_{C i}^{\min } \leq Q_{C i} \leq Q_{C i}^{\max } \quad i \in N_{C}$

Security Constraints:

$$
S_{I} \leq S_{I}^{\max } \quad i \in N_{I}
$$

\subsection{Gravitational Search Algorithm}

Rashedi et al developed a new meta-heuristic algorithm called GSA in year 2009 [22]. An analogy between Newton's gravitational laws with the optimization is presented in the algorithm. The algorithm says that every particle attracts towards each other and force exerted between two objects (agents) is proportional to the mass of the objects and inversely proportional to square of the distance between them. Force causes a global movement of all objects towards the objects with heavier mass. The agent which has higher fitness values, has heavier mass. GSA proposes four prepositions of a gravitational mass: its position, gravitational mass (active and passive) and inertial mass. Solution is gives by the position of mass and fitness of a function represented by the masses. It is assumed that given a system with $\mathrm{N}$ agents in search space represents solution to a problem [23]. Equation (17) represents space dimension and the position of the agent in $X_{i}^{d}$ and $d^{\text {th }}$ dimension.

$$
X_{i}=\left(X_{i} \ldots . X_{i}^{d} \ldots . . X_{i}^{n}\right) \quad \text { for } i=1,2,3 \ldots . N
$$

According to Newton's law of attraction, the force developed by $i^{\text {th }}$ mass due to $j^{\text {th }}$ mass at time $\mathrm{t}$ represented by Equation (18).

$$
F_{i j}^{d}=G(t) \frac{M_{p i}(t) * M_{q i}(t)}{R_{i j}^{d} * \ell}\left(X_{j}^{d}(t)-X_{i}^{d}(t)\right)
$$

Where $M_{p i}$ and $M_{q i}$ are active and passive gravitational mass. $G(t)$ is gravitational constant at time t. $R_{i j}$ is euclidian distance between $\mathrm{I}$ and $\mathrm{j}$ agents given by Equation (19).

$$
R_{i j}(t)=\left\|X_{i}(t), X_{j}(t)\right\|_{2}
$$

Force exerted on an agent $i$ is randomly weighted sum of the forces exerted from other agents which is given by Equation (20).

$$
F_{i}^{d}(t)=\sum_{j=i, j \neq i}^{m} \operatorname{rand}_{j} F_{i j}^{d}(t)
$$

Acceleration of the agent at time $\mathrm{t}$ in the $d^{\text {th }}$ dimension on law of motion is used directly to calculate the force. According to this law, acceleration is proportional to the force exerted and inversely proportional to mass of the agent.

$a_{i}^{d}(t)=\frac{F_{i}^{d}(t)}{M_{i i}(t)}$

Searching strategy of the algorithm is defined by updating velocity and position at time $\mathrm{t}$ and in dimension which is given in Equations (22) and (23).

$$
\begin{aligned}
& V_{i}^{d}(t+1)=\operatorname{rand}_{i} * V_{i}^{d}(t) * a_{i}^{d}(t) \\
& \mathrm{X}_{\mathrm{i}}^{\mathrm{d}}(\mathrm{t}+1)=\mathrm{X}_{\mathrm{i}}^{\mathrm{d}}(\mathrm{t}) * \mathrm{~V}_{\mathrm{i}}^{\mathrm{d}}(\mathrm{t}+1)
\end{aligned}
$$

The Gravitational constant $\mathrm{G}$ is given by

$$
\mathrm{G}(\mathrm{t})=\mathrm{G}\left(\mathrm{G}_{0}, \mathrm{t}\right)
$$

$\mathrm{G}(\mathrm{t})=\mathrm{G}_{0} \mathrm{e}^{-\frac{\alpha \mathrm{t}}{\mathrm{T}}}$

A heavy mass moves slower so at the end of iteration the masses obtain will be having high on gravity and value of fitness is more. Equation (26), (27), (28) and (29), where fit (t) represent fitness value of the agent at the time $t$ and best and worst masses in population.

For Minimization:

$$
\begin{aligned}
& \operatorname{worst}(t)=\max _{j=(1 \ldots m)} \text { fit }_{j}(t) \\
& \operatorname{best}(t)=\min _{j=(1 \ldots m)} f i t_{j}(t)
\end{aligned}
$$

For Maximization

$$
\begin{aligned}
& \operatorname{best}(t)={ }_{j=(1 \ldots m)}^{\max } \text { fit }_{j}(t) \\
& \operatorname{worst}(t)=\min _{j=(1 \ldots m)} \text { fit }_{j}(t)
\end{aligned}
$$

\section{RESULTS AND DISCUSSION}

A computer software programme has been developed in the MATLAB $2013^{\mathrm{R}}$ environment to perform the simulations and run on a Pentium IV CPU, $2.69 \mathrm{GHz}$, and $1.84 \mathrm{~GB}$ RAM computer. To demonstrate the effectiveness of the proposed technique, an IEEE 14 bus test system, IEEE 30 bus test system and a typical IEEE 118 bus test system have been used. The IEEE 14 Bus system represents a portion of the American Electric Power System which is located in the Midwestern US as of February, 1962. Basically this 14 bus system has 14 buses, 5 generators and 9 load buses. The IEEE 30 Bus system represents a portion of the American Electric Power System (in the Midwestern US) as of December, 1961. Basically this 30 bus system has 30 buses, 6 generators and 24 load buses. The IEEE 118 has the 118 buses, 51 generators and 67 load buses $[29,30]$. 


\subsection{Margin Enhancement using SVC}

Static VAR compensators (SVCs) are simply shunt connected static device which generates inductive or capacitive reactive power and measured in the form of volt ampere reactive (VAr). Static VAR compensators (SVCs) have been extensively used in electric power systems for reactive power compensation. Ibrahim B.M. Taha [31] and Md. M.Biswas [32] discussed the best locations of shunt SVCs for voltage stability enhancement. Mark Ndubuka [33] used the SVC for improvement of voltage stability and PSCAD/ EMTDC used to carry out simulations of the system. Bekri O.L. [34] used Continuation Power Flow for the study of voltage stability assessment with appropriate representation of SVC and TCSC. Chaparro E.R. [35] discussed the coordinated tuning of a set of Stativ Var Compensators using Evolutionary Algorithms. J. Vara Prasad [36] discussed the enhancement of Critical loading margin (CLM) using SVCs and CLM derived from Repeated Power Flow (RPF). B.T. Ooi [37] used SVC in long distance radial transmission system for damping improvement. Hemat Barot and Lake singh [38] discussed the global scenario of SVCs in Ontario, Canada. Prechanon Kumkratug [39] gives the mathematical model of power system with SVC in long transmission lines. Figure 4 shows the basic structure of SVC.

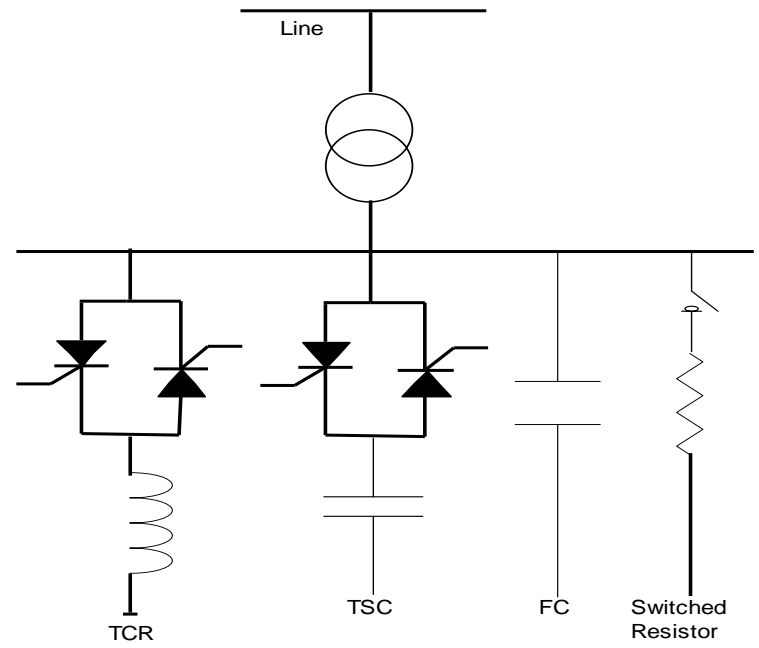

Fig 4: Basic structure of a SVC

\subsubsection{Case study on IEEE-14 Bus system}

To validate the proposed approach two operating scenarios are considered.

Case1. Base case (where the load buses are having the nominal values of real and reactive power)

Case2. High Reactive Loading (increase of the system's reactive load by ( 3.2 p.u. from base case)

Tables 1 and 2 give the Line stability index FVSI and Lmn for IEEE 14 test bus system at for two cases, respectively. Following results are emerged from this analysis.

- Most five weakest buses in IEEE-14 bus system are bus no. 14, 12, 11, 10 and 13 according to their loadability.

- At the base case no weak bus is found.
Table 1. Line stability indices for IEEE 14 test bus system with base load condition

\begin{tabular}{cccc}
\hline From & To & FVSI & $\mathbf{L}_{\mathbf{m n}}$ \\
\hline $\mathbf{5}$ & 1 & 0.006 & 0.006 \\
$\mathbf{9}$ & 4 & 0.038 & 0.039 \\
$\mathbf{1 3}$ & 6 & 0.055 & 0.054 \\
$\mathbf{1 0}$ & 11 & 0.052 & 0.051 \\
$\mathbf{1 1}$ & 6 & 0.071 & 0.07 \\
$\mathbf{1 2}$ & 6 & 0.033 & 0.033 \\
$\mathbf{1 4}$ & 13 & 0.074 & 0.073 \\
\hline
\end{tabular}

Table 2. Line stability indices for IEEE 14 test bus system with heavy reactive loading

\begin{tabular}{ccccc}
\hline Ranking & $\begin{array}{c}\text { Bus } \\
\text { (Load) }\end{array}$ & Qm & FVSI & $\mathbf{L}_{\mathbf{m n}}$ \\
\hline $\mathbf{1}$ & 14 & 0.75 & 0.999 & 0.987 \\
$\mathbf{2}$ & 12 & 0.912 & 0.989 & 0.986 \\
$\mathbf{3}$ & 11 & 1.008 & 0.996 & 0.976 \\
$\mathbf{4}$ & 10 & 1.392 & 0.933 & 0.973 \\
$\mathbf{5}$ & 13 & 1.4732 & 0.997 & 0.976 \\
\hline
\end{tabular}

Table 3. The best optimal size of SVCs for IEEE 14 test bus system by GSA

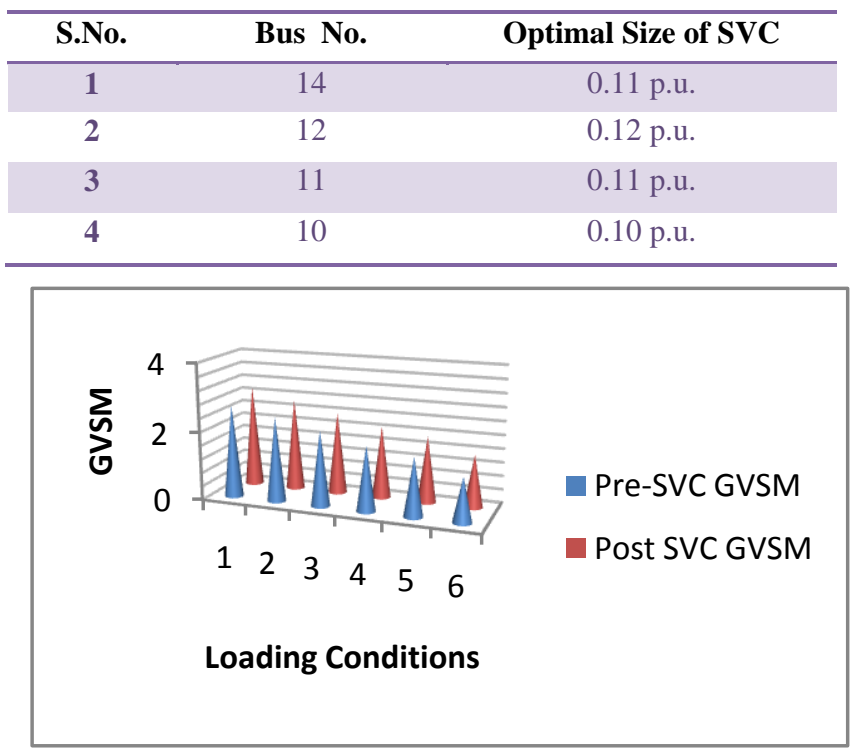

Fig 5: Improved GVSM for IEEE 14 Bus system

By employing SVCs on buses 14, 1211 and 10 the margin can be improved substantially. The plots of GVSM and Critical voltages are shown in figure 5 and 6 . Significant increases in the critical parameters are observed after the application of SVC. 


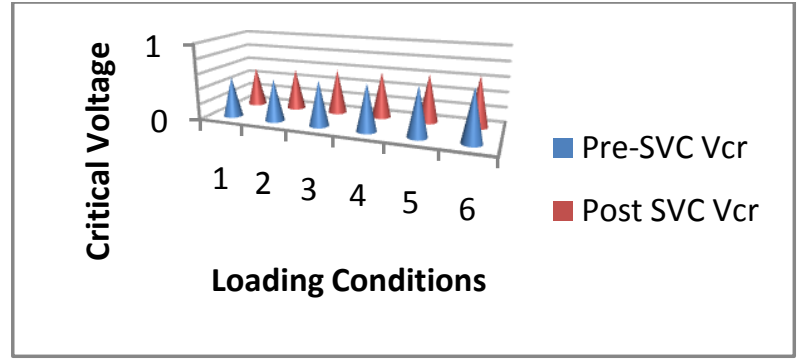

Fig 6: Improved $V_{\text {cr }}$ for IEEE 14 Bus system

\subsubsection{Case study on IEEE-30 Bus system}

To validate the proposed approach two operating scenarios are considered.

Case1. Base case (where the load buses are having the nominal values of real and reactive power)

Case2. High Reactive Loading (increase of the system's reactive load by ( 2.7 p.u. from base case)

Tables 4 and 5 give the Line stability index FVSI and Lmn for IEEE 30 test bus system at for two cases, respectively. Following results are emerged from this analysis.

- Most five weakest buses in IEEE-30 bus system are bus no. 26, 30, 29, 20 and 18 according to their loadability.

- At the base case no buses are weak as indicated by the low values of Line stability indices.

Table 4. Line stability indices for IEEE 30 test bus system with base load condition

\begin{tabular}{cccc}
\hline From & To & FVSI & $\mathbf{L}_{\mathbf{m n}}$ \\
\hline $\mathbf{6}$ & 28 & 0.024 & 0.024 \\
$\mathbf{7}$ & 5 & 0.065 & 0.066 \\
$\mathbf{1 0}$ & 9 & 0.024 & 0.024 \\
$\mathbf{1 2}$ & 13 & 0.052 & 0.052 \\
$\mathbf{1 2}$ & 16 & 0.029 & 0.03 \\
$\mathbf{1 6}$ & 17 & 0.012 & 0.012 \\
$\mathbf{2 0}$ & 10 & 0.032 & 0.032 \\
$\mathbf{2 0}$ & 19 & 0.009 & 0.009 \\
$\mathbf{2 5}$ & 24 & 0.027 & 0.027 \\
$\mathbf{2 8}$ & 27 & 0.085 & 0.085 \\
$\mathbf{2 9}$ & 27 & 0.032 & 0.031 \\
$\mathbf{3 0}$ & 27 & 0.042 & 0.041 \\
$\mathbf{3 0}$ & 29 & 0.013 & 0.013 \\
\hline
\end{tabular}

Table 5. Line stability indices for IEEE 30 test bus system with heavy reactive loading

\begin{tabular}{ccccc}
\hline Ranking & Bus & $\mathbf{Q}_{\mathbf{m}}$ & FVSI & $\mathbf{L}_{\mathbf{m n}}$ \\
\hline $\mathbf{1}$ & 26 & 0.2622 & 0.985 & 0.999 \\
$\mathbf{2}$ & 30 & 0.2831 & 0.971 & 0.992 \\
$\mathbf{3}$ & 29 & 0.324 & 0.999 & 0.997 \\
$\mathbf{4}$ & 20 & 0.8043 & 0.998 & 0.999 \\
$\mathbf{5}$ & 18 & 0.8145 & 0.994 & 0.998 \\
\hline
\end{tabular}

Table 6. The best optimal size of SVCs for IEEE 30 test bus system by GSA

\begin{tabular}{ccc}
\hline S.No. & Bus No. & Optimal Size of SVC \\
\hline $\mathbf{1}$ & 26 & 0.11 p.u. \\
$\mathbf{2}$ & 30 & 0.10 p.u. \\
$\mathbf{3}$ & 29 & 0.10 p.u. \\
$\mathbf{4}$ & 20 & 0.13 p.u. \\
$\mathbf{5}$ & 18 & 0.12 p.u. \\
\hline
\end{tabular}

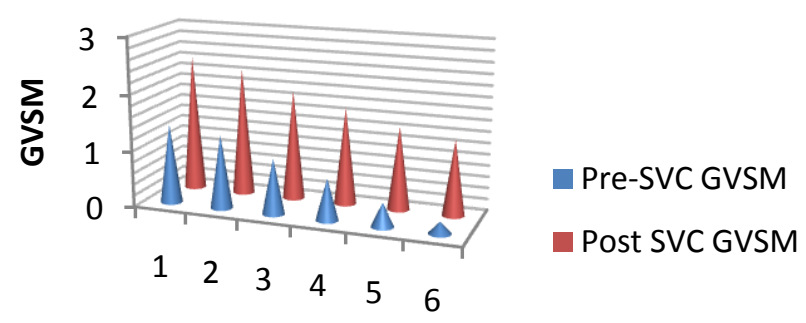

Loading Conditions

Fig 7: Improved GVSM for IEEE 30 Bus system

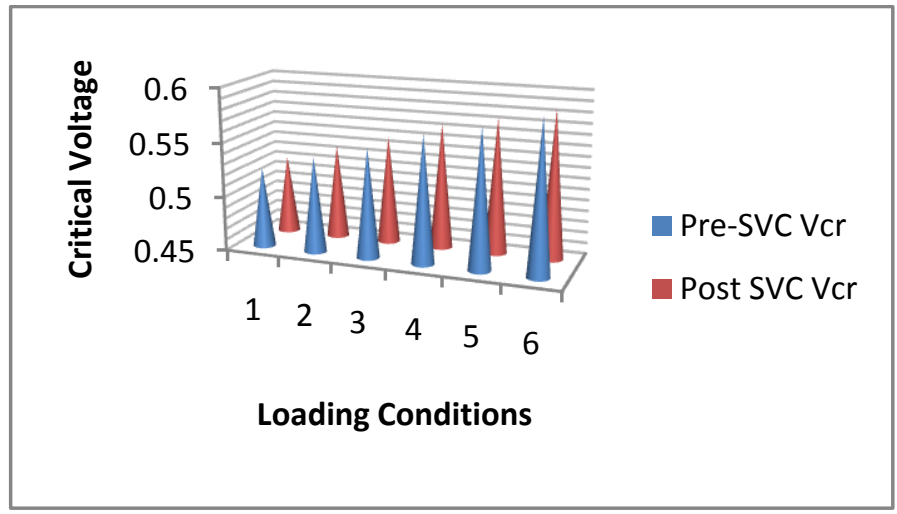

Fig 8: Improved $V_{\text {cr }}$ for IEEE 30 Bus system

Table 4 and 5 show the values of location predictors (line stability indices) at base and reactive loading. Figure 7 and 8 show the increment in GVSM and critical voltage.

\subsubsection{Case study on IEEE-118 Bus system}

Following cases are formulated to test the efficacy of the proposed approach.

Case1. Base case (where the load buses are having the nominal values of real and reactive power)

Case2. High Reactive Loading (increase of the system's reactive load by (1.77 p.u. from base case)

Tables 7 and 8 give the Line stability index FVSI and $\mathrm{L}_{\mathrm{mn}}$ for IEEE 118 test bus system at for two cases, respectively. Following results are emerged from this analysis.

- Most five weakest buses in IEEE-118 bus system are bus no. 117, 43, 22, 20 and 86 according to their loadability.

- At the base case no buses are weak. 
Table 7. Line stability indices for IEEE 118 test bus system with base load condition

\begin{tabular}{cccc}
\hline From & To & FVSI & Lmn \\
\hline $\mathbf{3}$ & 12 & 0.101 & 0.1 \\
$\mathbf{5}$ & 8 & 0.124 & 0.125 \\
$\mathbf{1 3}$ & 11 & 0.036 & 0.036 \\
$\mathbf{2 5}$ & 26 & 0.026 & 0.026 \\
$\mathbf{3 0}$ & 8 & 0.142 & 0.141 \\
$\mathbf{3 7}$ & 38 & 0.136 & 0.137 \\
$\mathbf{3 8}$ & 65 & 0.282 & 0.279 \\
$\mathbf{5 1}$ & 49 & 0.113 & 0.107 \\
$\mathbf{5 4}$ & 49 & 0.198 & 0.189 \\
$\mathbf{5 5}$ & 59 & 0.084 & 0.082 \\
$\mathbf{6 2}$ & 66 & 0.158 & 0.154 \\
$\mathbf{6 6}$ & 65 & 0.095 & 0.095 \\
$\mathbf{6 7}$ & 66 & 0.078 & 0.077 \\
$\mathbf{6 9}$ & 68 & 0.136 & 0.136 \\
$\mathbf{7 5}$ & 69 & 0.185 & 0.178 \\
$\mathbf{7 7}$ & 69 & 0.198 & 0.205 \\
$\mathbf{8 0}$ & 81 & 0.098 & 0.098 \\
$\mathbf{8 6}$ & 87 & 0.131 & 0.131 \\
$\mathbf{9 6}$ & 80 & 0.25 & 0.252 \\
$\mathbf{9 9}$ & 80 & 0.195 & 0.202 \\
$\mathbf{9 4}$ & 100 & 0.12 & 0.119 \\
$\mathbf{9 7}$ & 80 & 0.134 & 0.134 \\
$\mathbf{9 8}$ & 80 & 0.086 & 0.087 \\
$\mathbf{1 0 6}$ & 105 & 0.023 & 0.023 \\
$\mathbf{1 1 4}$ & 32 & 0.028 & 0.028 \\
$\mathbf{1 1 5}$ & 27 & 0.002 & 0.002 \\
$\mathbf{1 1 8}$ & 75 & 0.08 & 0.08 \\
\hline
\end{tabular}

Table 8. Line stability indices for IEEE 118 test bus system with heavy reactive loading

\begin{tabular}{ccccc}
\hline Ranking & Bus & Qm & FVSI & Lmn \\
\hline $\mathbf{1}$ & 117 & 1 & 0.991 & 0.994 \\
$\mathbf{2}$ & 43 & 1.19 & 0.908 & 0.915 \\
$\mathbf{3}$ & 22 & 1.25 & 0.903 & 0.913 \\
$\mathbf{4}$ & 20 & 1.5 & 0.972 & 0.986 \\
$\mathbf{5}$ & 86 & 1.5 & 0.934 & 0.94 \\
$\mathbf{6}$ & 53 & 1.54 & 0.901 & 0.909 \\
$\mathbf{7}$ & 44 & 1.68 & 0.939 & 0.97 \\
$\mathbf{8}$ & 21 & 1.68 & 0.878 & 0.907 \\
$\mathbf{9}$ & 101 & 1.8 & 0.941 & 0.974 \\
$\mathbf{1 0}$ & 33 & 1.89 & 0.958 & 0.974 \\
\hline
\end{tabular}

Table 9. The best optimal size of SVCs for IEEE 118 test bus system by GSA

\begin{tabular}{ccc}
\hline S.No. & Bus No. & Optimal Size of SVC \\
\hline $\mathbf{1}$ & 117 & 0.80 p.u. \\
$\mathbf{2}$ & 43 & 0.83 p.u. \\
$\mathbf{3}$ & 22 & 0.79 p.u. \\
\hline
\end{tabular}

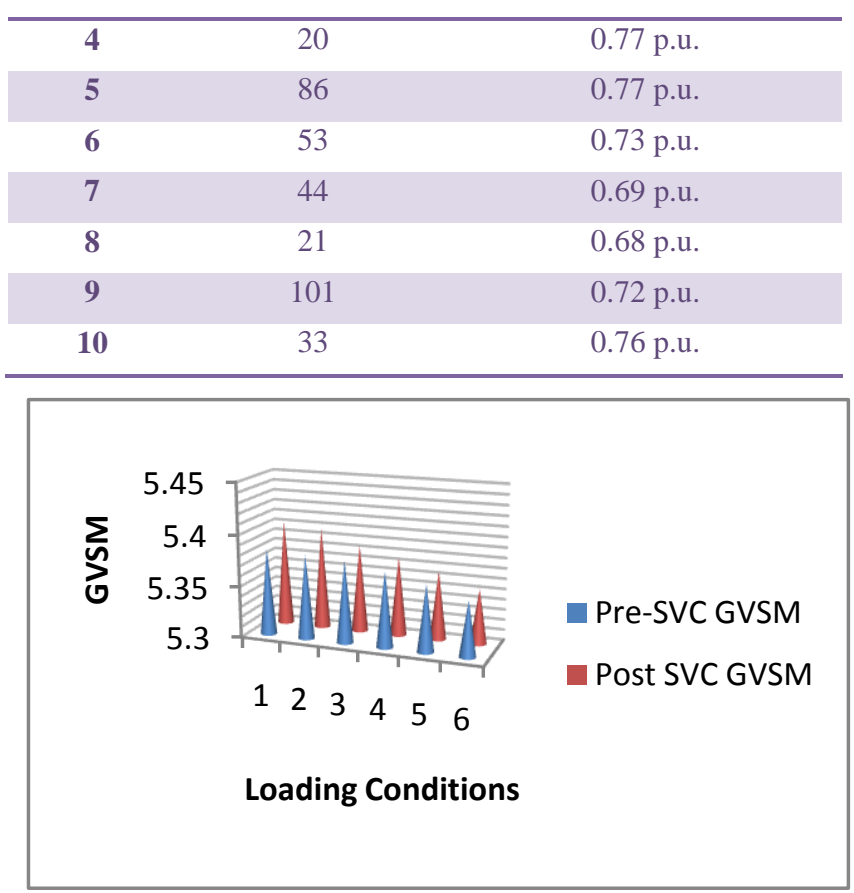

Fig 9: Improved GVSM for IEEE 118 Bus system

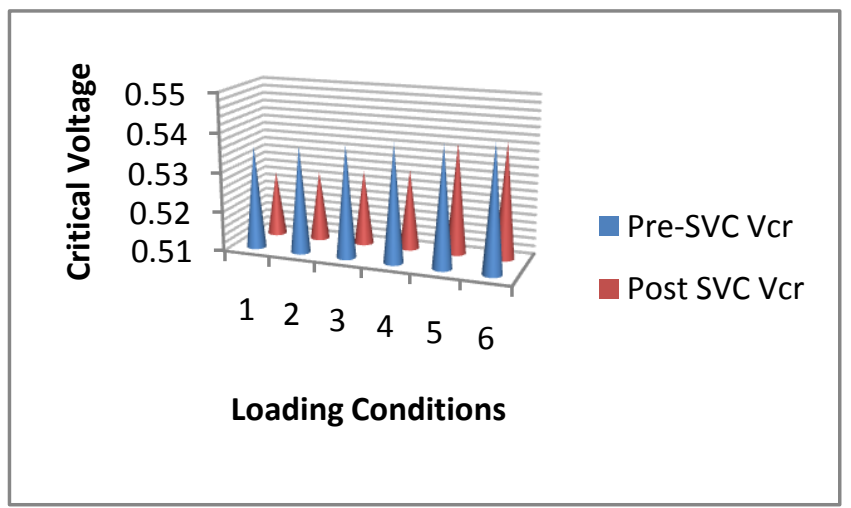

Fig 10: Improved $V_{\text {cr }}$ for IEEE 118 Bus system

Table No. 3, 6 and 9 are giving the optimal value of SVCs by using Gravitational Search Algorithm. These tables also give the locations of weak buses and optimal size of SVCs at those locations.

Figure 5, 7 and 9 show the GVSM plots for IEEE 14, 30 and 118 bus systems, with and without SVCs. Figure 6, 8 and 10 show the Critical voltage plots for IEEE 14, 30 and 118 bus systems, with and without SVCs. It is observed that the presence of SVC on weak locations enhances system stability and improve the critical voltage.

\section{CONCLUSION}

Voltage stability assessment and enhancement are two critical issues in the context of modern power system. These issues are addressed in this paper with the incorporation of simulation modules. Following are the major highlights of this work.

(a) Two line stability indices FVSI and $\mathrm{L}_{\mathrm{mn}}$ are employed for weak bus identification. FVSI and $\mathrm{L}_{\mathrm{mn}}$ for the load buses in power system network are calculated to judge the health of the power system. Ranking of weakest buses in particular power system are decided by these indices. 
(b) The system is simulated with high reactive loading. In this operating condition the value of GVSM becomes lower and the system is on the verge of collapse. The application of SVCs on weak buses is a corrective action for this condition. The choice of size of SVC is calculated by optimization problem (GSA) for IEEE 14, 30 , and 118 bus systems.

(c) The proposed approach provides fast computation of voltage stability assessment. Once analyzed the system stability properly then operator can use the remedy to avoid the voltage collapse.

The proposed approach can be a beneficial tool for the assessment and enhancement voltage stability. The extension of the approach on real power system lays in the scope of future.

\section{ACKNOWLEDGMENTS}

The authors acknowledge the support and encouragement of Malaviya National Institute of Technology, Jaipur, Swami Keshvanand Institute of Technology, Management \& Gramothan, Jaipur, Rajasthan, India.

\section{NOMENCLATURE:}

$\begin{array}{ll}\mathbf{R} & \text { Resistance of the line } \\ \mathbf{X} & \text { Reactance of the line } \\ \mathrm{Z} & \text { Impedance of the line }\end{array}$

$\mathbf{V}_{\mathbf{1}}, \mathbf{V}_{\mathbf{2}}$ Voltage at sending bus and receiving bus respectively

$\mathbf{Q}_{2} \quad$ Reactive Power at receiving bus

$\boldsymbol{\delta} \quad$ Voltage Angle

"s", "r" Symbol for sending and receiving side respectively

$V_{G} \quad$ Generator Voltage Vector except Slack Bus

$T_{k} \quad$ Transformer Tap Vector

$Q_{c} \quad$ Shunt Capacitor/Inductor Vector

$Q_{G} \quad$ Generator Reactive Power Vector

$P_{G i} \quad$ Injective Active Power at Bus i

$P_{D i} \quad$ Demanded Active Power at Bus I

$V_{i} \quad$ Voltage at Bus i

$Q_{G i} \quad$ Injective Reactive Power at Bus I

$Q_{D i} \quad$ Demanded Reactive Power at Bus i

N-R Newton Raphson

FVSI Fast Voltage Stability Index

$\mathbf{L}_{\mathbf{m n}} \quad$ Line Stability Indicator

GVSM Global Voltage Stability Margin

\section{REFERENCES}

[1] P. Nagendra et al.2011. An innovative technique to evaluate network equivalent for voltage stability assessment in a widespread sub-grid system. Electrical Power and Energy Systems, ELSEVIER, Vol. 33, pp. 737-744.

[2] M.H. Haque, 2004. Use of V-I characteristic as a tool to assess the static voltage stability limit of a power system. IEE Proc.-Gener. Transm. Distrib., Vol. 151, No. 1.

[3] P.Kundur, 1994. Power System Stability and Control. Mc.Graw-Hill, ISBN-13:9780070635159, NewYork, USA.

[4] Gubina F, Strmcnik B. 1995. Voltage collapse proximity index determination using voltage phasors approach. IEEE Trans Power Syst 1995;10(2):788-94.

[5] Gubina F, Strmenik B. 1997. A simple approach to voltage stability assessment in radial networks. IEEE Trans Power Syst 1997;12(3):1121-8.

[6] Vadivelu K R et al. 2014. Maximum loadability estimation for weak bus identification using Fast Voltage Stability Index in a power transmission system by real time approach. IJEETC, ISSN 2319 - 2518, Vol. 3, No. 1.

[7] Fozdar M. and C.M Arora 2006. Improvement of Voltage stability and Effects of Loadability. IEEE Universities Power Engineering Conference (UPEC-06), Volume: 2,Pages: 486 - 490.

[8] Reis Claudia, 2006. A Comparison of Voltage Stability Indices", IEEE MELECON 2006, May 16-19, Benalmadena (Malaga), Spain.

[9] P. Kessel and H. Glavitsch, 1986. Estimating the voltage stability of a power system. IEEE Transactions on Power Delivery, Vol.PWRD-1, No.3, pp. 346- 353.

[10] N. D. Hatziargyriou and T. Van Cutsem, 1994. Indices for predicting voltage collapse including dynamic phenomena. Technical report TF-38-02-11, CIGRE.

[11] M. Moghavvemi, 1997. New method for indicating voltage stability in power system. Proceedings of IEEE International Conference on Power Engineering, Singapore, IPEC, 1997, pp. 223-227.

[12] Musirin Ismail et al 2002. On-Line Voltage Stability Based Contingency Ranking Using Fast Voltage Stability Index (FVSI). International conference on "IEEE/PES Transmission and Distribution Conference and Exhibition 2002, Asia Pacific. Vol: 2, Pages: $1118-$ 1123.

[13] Musirin Ismail et al 2002. Novel Fast Voltage Stability Index (FVSI) for Voltage Stability Analysis in Power Transmission System. IEEE Student Conference on Research and Developing Proceeding 2002, Pages: 265 268.

[14] A. Mohamed, G. B. Jasmon and S. Yusoff, 1989. A static voltage collapse indicator using line stability factors. Journal of Industrial Technology, Vol. 7, No. 1, pp. 7385 .

[15] Nandlal Krishna et al 2014. Assessment of Voltage Stability of a Small Island Network using a Developed 
MATLAB Toolbox. IEEE Transmission \& Distribution Conference and Exposition-Latin America IEEE PES.

[16] Lim Z. J. et al2012. Evaluation of the Effectiveness of Voltage Stability Indices on Different Loadings. IEEE International power engineering and optimization conference (PEOCO 2012), Melaka, Malaysia.

[17] Suganyadevi M.V. et al 2009. Estimating of Loadability Margin of a Power System by comparing Voltage Stability Indices. International conference on "control, automation, communication and energy conservation 2009.

[18] Tiwari R. et al 2012. Line Collapse Proximity Index for Prediction of Voltage Collapse in Power Systems. Electrical Power and Energy Systems, ELSEVIER, Vol. 41, pp. 105-111.

[19] Rahi O. P. et al 2011. Power System Voltage Stability Assessment through Artificial Neural Network.International Conference on Communication Technology and System Design 2011, ELSEVIER Procedia Engineering, Vol. 30, pp. 53-60.

[20] Arya L. D. et al, 2010. Loadability margin enhancement using co-ordinated aggregation based particle swarm optimization (CAPSO). Electrical Power and Energy Systems, ELSEVIER, Vol. 32, pp. 975-984.

[21] Chang C.S. et al 1998. Optimal multi objective SVC planning for voltage stability enhancement. IEEE Proceedings on Generation, Transmission and Distribution, Vol. 145, No.2.

[22] E Rashedi, H Nezamabadi-pour and S Saryazdi, 2009. GSA: A Gravitational Search Algorithm. Information Science, Vol. 179, p. 2232- 2248.

[23] Saxena Aakash et al, 2015. A chronological review and comparison of four Evolutionary based algorithms. European Journal of Advances in Engineering and Technology, Vol. 2(1), Page No. 35-41, 2015.

[24] Binod Shaw et al, 2014. Solution of reactive power dispatch of power systems by an opposition based gravitational search algorithm. Electrical Power and Energy Systems, ELSEVIER, Vol. 55, pp. 29-40.

[25] Serhat Duman et al, 2012. Optimal power flow using gravitational search algorithm. Energy Conversion and Management, ELSEVIER, Vol. 59, pp. 86-95.

[26] E Rashedi, H Nezamabadi-pour and S Saryazdi, 2011. Filter modeling using gravitational search algorithm. Engineering Applications of Artificial Intelligence, ELSEVIER, Vol. 24, pp. 117-122.

[27] Biplab Bhattacharyya et al 2015. Reactive power planning with FACTS devices using gravitational search algorithm. Ain Shams Engineering Journal vol. 6, pp. 865-871.

[28] Ambika Ramamoorthy et al 2014. Reactive Power Optimization Using GSA. IEEE 978-1-4799-6042-2/14.

[29] Power system Test Archive-UWEE, University of Washington http://www.ee.washington.edu/research/pstca>.

[30] www.mathworks.com

[31] Ibrahim B.M.Taha, 2015. Best locations of shunt SVCs for steady state voltage stability enhancement. IEEE 978 $1-4799-8598-2$.

[32] Md. M.Biswas et al, 2011. Voltage level improving by using static VAR compensator (SVC). Global Journal of researches in engineering, Volume 11 Issue 5 Version 1.0, ISSN: 0975-5861.

[33] Mark Ndubuka, 2009. Voltage Stability Improvement using Static Var Compensator in Power Systems. Leonardo Journal of Sciences, ISSN 1583-0233, Issue 14, pp. 167-172.

[34] Beki O.L. et al, 2010. Optimal location of SVC and TCSC for Voltage Stability Assessment. IEEE The 4th International Power Engineering and Optimization Conference (PEOCO2010), Shah Alam, Selangor, MALAYSIA.

[35] Chaparro E.R. et al, 2011. Coordinated tuning of a set of Static Var Compensators using Evolutionary Algorithms. IEEE Trondheim PowerTech, 978-1-4244-8417-1/11.

[36] J. Vara Prasad et al, 2013. Optimal Allocation of FACTS Controllers for Critical Loading Margin Enhancement. IEEE International Conference on Power, Energy and Control (ICPEC), 978-1-4673-6030-2/13.

[37] B.T. Ooi et al, 1984. Co-Ordination of Static Var Compensators with Long Distance Radial Transmission System for Damping Improvement. IEEE Power Engineering Review, pp-265-274.

[38] Hemat Barot et al, 2014. Operational experience withstatic Var compensators in Ontario, Canada. IEEE 978-1-4799-6415-4/14.

[39] Prechanon Kumkratug 2012. The Mathematical Model of Power System with Static Var Compensator in Long Transmission Line. American Journal of Applied Sciences Vol. 9 (6): pp. 846-850, ISSN 1546-9239. 